\title{
OXIDAÇ̃̃O PROTÉICA E PEROXIDAÇ̃̃O LIPÍDICA EM PLANTAS DE DIFERENTES CICLOS DE SELEÇÃO DO MILHO 'SARACURA', SOB ENCHARCAMENTO CONTÍNUO
}

\author{
MARCUS JOSÉ CONCEIÇÃO LOPES ${ }^{1}$, ISABEL REGINA PRAZERES DE SOUZA², PAULO CÉSAR \\ MAGALHÃES ${ }^{2}$, ELTO EUGÊNIO GOMES E GAMA², JOSÉ DONIZETI ALVES ${ }^{3}$, MARCELO \\ MURAD MAGALHÃES ${ }^{3}$
}

\author{
${ }^{1}$ Biólogo, MSc., Doutorando em Agronomia/Fisiologia Vegetal, Universidade Federal de Lavras. CEP: 37200-000 \\ Lavras, MG.E-mail: marcus.jose@posgrad.ufla.br \\ ${ }^{2}$ Pesquisadores, Embrapa Milho e Sorgo. Caixa Postal 157, CEP: 35701-970 Sete Lagoas, MG. E-mail: \\ isabel@cnpms.embrapa.br (autor paracorrespondência)
}

${ }^{3}$ Departamento de Biologia, Universidade Federal de Lavras. Caixa Posta 37, CEP: 37.200-000 Lavras, MG.

Revista Brasileira de Milho e Sorgo, v.4, n.3, p.362-373, 2005

RESUMO - Este trabalho teve por objetivo estudar, sob encharcamento contínuo, mecanismos bioquímicos, como concentração de proteína total, oxidação protéica e peroxidação de lipídeos de membrana, em folha e em raiz de plântulas, nos estádios V3-V5, da variedade de milho BRS 4154 (Saracura) após o primeiro (C1), oitavo (C8) e décimo sexto (C16) ciclos de seleção sob encharcamento intermitente, tendo como testemunha a variedade BR 107. Sementes dos ciclos de seleção do Saracura, C1, C8 e C16 e da testemunha, BR 107, foram plantadas com o embrião voltado para cima, a uma profundidade aproximada de $1 \mathrm{~cm}$ da superfície do solo, em copos de plástico de $200 \mathrm{ml}$, perfurados na base e preenchidos com solo de várzea. Os tratamentos constituíram-se de diferentes períodos de encharcamento: $0 \mathrm{~h}$ (sem encharcamento) e 8, 24, $48,72,96,120$ e $144 \mathrm{~h}$ sob encharcamento contínuo, utilizando-se água destilada até a superfície do solo. Os resultados do teor e oxidação protéicos, da peroxidação lipídica radicular e foliar foram responsivos ao encharcamento e mostraram adaptações das plântulas de milho ao estresse prolongado, obtendo-se, de maneira geral, a mesma tendência em todos os genótipos.

Palavras-chave: estresse oxidativo, Zea mays L., variedade, plântula.

\section{PROTEIN OXIDATION AND LIPID PEROXIDATION OF SEVERAL 'SARACURA'MAIZE SELECTION CYCLES UNDER CONTINUOUS FLOODING}

\begin{abstract}
This work aimed at studying, under continuous flooding, biochemical mechanisms such as total protein concentration, proteic oxidation, and membrane lipid peroxidation in leaf and root of the maize BRS 4154 (Saracura) seedlings, after 1 (C1), 8 (C8) and 16 (C16) selection cycles under intermittent flooding. The variety BR 107 was used as control. Seeds of the selection cycles from Saracura: C1, C8 and C16, and control BR 107 were sowed with the embryo facing up, $1 \mathrm{~cm}$ deep, in perforated $200 \mathrm{ml}$ plastic cups filled with lowland soil. The treatments were composed of the periods $0 \mathrm{~h}$ (without flooding) $8,24,48,72,96,120$ and $144 \mathrm{~h}$ under continuous flooding, using distilled water up to the soil surface. Protein oxidation and concentration, root and leaf lipid
\end{abstract}


peroxidation were responsive to flooding, showing the same tendency in all genotypes analyzed.

Key words: oxidative stress, Zea mays L., variety, seedlings.

O grande desafio para a elevação do rendimento agrícola e o aumento da competitividade do milho produzido no Brasil é o ajuste de sistemas de produção, de forma a atender condições produtivas e de uso. Dentre esses aspectos, podem ser citados a produção de forragem para alimentação bovina, o plantio direto, a safrinha e a produção de grãos com maior resistência a pragas, doenças e em condições de estresse mineral e ambiental.

Os solos encharcados representam uma condição de estresse para diversas culturas e, excetuando-se o arroz, a produção de outras espécies cultivadas nessas condições torna-se pouco viável. No Brasil, poucos são os estudos sobre a influência do encharcamento na produtividade das plantas cultivadas e raros são os testes de espécies e cultivares para tolerância a essas condições de solo. Uma das razões desse pouco interesse tem sido a utilização das várzeas quase que exclusivamente com arroz e pastagem nativa (Silva, 1986). No país, existem 28 milhões de hectares de várzeas para a utilização agrícola e o milho, se tolerante ao encharcamento intermitente, seria uma alternativa interessante para melhor aproveitamento dessas áreas.

Em 1986, pesquisadores da equipe multidisciplinar da Embrapa Milho e Sorgo, por meio do programa de melhoramento, iniciaram o desenvolvimento de um composto de milho de ampla base genética (mistura balanceada de 36 populações amarelas), denominado BRS 4154 (Saracura), para cultivo em área de várzea (Parentoni et al., 1995), o qual já está sendo comercializado desde 1997. A variedade Saracura vem passando por um processo de seleção massal, sob encharcamento intermitente, que já se encontra no décimo sétimo ciclo.

Desde 1997, o Setor de Fisiologia Vegetal da Universidade Federal de Lavras, em conjunto com a Embrapa Milho e Sorgo, vem estudando os possíveis mecanismos de tolerância do Saracura ao encharcamento e, diversos trabalhos já foram realizados.

$\mathrm{O}$ estresse oxidativo é resultante do aumento de espécies reativas de oxigênio (EROS), que podem causar danos às proteínas e peroxidação lipídica (Smirnoff, 1993). Dentre os fatores que podem gerar estresse oxidativo estão a radiação ultravioleta, a seca, o encharcamento, os impactos osmóticos, as mudanças drásticas de temperatura, bem como as mudanças químicas e ambientais (Elstner \& Osswald, 1994). Segundo Henriques et al. (2001), as proteções celulares contra os efeitos deletérios das EROS incluem a prevenção (evitar a formação), a interceptação (neutralização, por meio de enzimas antioxidantes ou por antioxidantes de baixo peso molecular, como as vitaminas $\mathrm{C}$ e $\mathrm{E}$, carotenóides, glutationa reduzida e outros) e reparação (minimização dos efeitos).

O estresse oxidativo pode causar danos às proteínas (Smirnoff, 1993) e as EROS causam uma maior sensibilidade às proteínas, que oxidam e podem se fragmentar (Davies, 1987), contribuindo para aumentar o pool de enzimas de degradação (Stadtman, 1992). As modificações oxidativas são caracterizadas pela formação de carbonil nas cadeias de histidina, arginina, lisina e prolina (Amici et al., 1989; Shacter et al., 1994). A detecção do grupo carbonil, pela conversão aos derivados do 2,4-dinitrofenilhidrazina, tem sido 
usada para a quantificação de oxidação protéica (Levine et al., 1990). Alguns trabalhos têm mostrado a formação de carbonil, indicando oxidação protéica em feijão (Phaseolus vulgaris L.), quando as plantas foram submetidas a altas doses de ozônio (Junqua et al., 2000; Leitão et al., 2003).

A produção de EROS pode iniciar o processo de peroxidação lipídica nas membranas celulares, formando hidroperóxidos de lipídeos. A peroxidação de lipídeos de membrana é um dos eventos mais significativos do estresse oxidativo, porque causa a diminuição da fluidez, modificações de permeabilidade iônica e de outras funções associadas às membranas (Queiroz et al., 1998). Os eventos bioquímicos resultantes de diminuição da fluidez das membranas incluem a interferência nas funções das proteínas, a redução do suprimento de energia, a perda de compartimentalização, a liberação acentuada de íns e outros eventos que rompem o metabolismo normal e levam ao desbalanço e perda das funções essenciais (Aziz \& Larher, 1998).

Na literatura, são encontrados vários trabalhos que relatam a peroxidação lipídica sob várias condições de estresse: encharcamento e senescência, em tabaco (Nicotiana tabacum) (Hurng \& Kao, 1994), seca, em aroeira do sertão (Myracroduon urundeuva Fr.) (Queiroz et al., 2002), estresse salino, em Beta vulgaris L. e Beta maritima L. (Bor et al., 2003), estresse por alumínio e encharcamento, em milho (Boscolo et al., 2003; Yan et al., 1996).

Este trabalho teve por objetivo estudar, sob encharcamento contínuo, aspectos bioquímicos, como concentração de proteína total, oxidação protéica, peroxidação de lipídeos de membrana em folha e em raiz de plântulas do milho BRS 4154 (Saracura) após o C1, C8 e C16 ciclos de seleção ao encharcamento intermitente, tendo com testemunha a cultivar BR 107.

\section{Material e Métodos}

O experimento foi conduzido em casade-vegetação, sob condições controladas de umidade e temperatura. Sementes dos ciclos de seleção do Saracura (C1, C8 e C16) e da testemunha, BR 107, foram plantadas com o embrião voltado para cima, a uma profundidade aproximada de 1 $\mathrm{cm}$ da superfície do solo, em copos de plástico de $200 \mathrm{ml}$, perfurados na base, segundo metodologia descrita por Porto (1997). Os copos foram previamente preenchidos com solo de várzea, cuja adubação (400 $\mathrm{kg} \mathrm{ha}^{-1}$ de 5-20-20), foi feita após a análise química do solo. Foram plantadas quatro sementes por copo, com posterior desbaste para duas plântulas/copo. Após a germinação, os copos, com as plântulas no estádio V3, foram transportados para bandejas e encharcados até a superfície do solo.

Os tratamentos constituíram-se de diferentes períodos: $0 \mathrm{~h}$ (sem encharcamento), 8, 24, $48,72,96,120$ e $144 \mathrm{~h}$ de encharcamento contínuo, para proteína total e oxidação protéica, e de $0,8,24,48$ e $72 \mathrm{~h}$, para peroxidação radicular e foliar, utilizando-se água destilada até a superfície do solo, sempre mantendo a altura da lâmina d'água nos copos.

A primeira coleta foi realizada nas plântulas no estádio V3, o que, nessas condições correspondeu a seis dias após o plantio e a dois dias após a germinação. No final do experimento, as plântulas encontravam-se no estádio V5. As plântulas foram cuidadosamente retiradas dos copos e as raízes lavadas em água destilada e imediatamente acondicionadas em papel alumínio, posteriormente imersas em $\mathrm{N}_{2}$ líquido e armazenadas em ultrafreezer $-80^{\circ} \mathrm{C}$, até a realização das análises. As folhas coletadas para análises de peroxidação lipídica foram acondicionadas da mesma maneira que as raízes.

Revista Brasileira de Milho e Sorgo, v.4, n.3, p.362-373, 2005 
O delineamento experimental foi inteiramente casualizado (DIC), com três repetições e utilizadas dez plântulas por repetição.

Para a análise de variância e comparação das médias, foi utilizado o programa SISVAR e, para o ajuste de equações dos dados obtidos na peroxidação lipídica radicular e foliar, foi utilizado o programa TableCurve.

Para a extração protéica, foram macerados $300 \mathrm{mg}$ de ápices de raízes em nitrogênio líquido, seguido da adição de $900 \mathrm{ml} \mathrm{de}$ tampão fosfato de potássio $25 \mathrm{mM}$, pH 7,0. As amostras foram submetidas a centrifugação, a $16.000 \mathrm{~g}$, a $4{ }^{\circ} \mathrm{C}$ por $30 \mathrm{~min}$. O sobrenadante obtido desse homogenato foi utilizado para análise do teor e oxidação protéicos.

O teor protéico foi analisado pelo método de Bradford (1976), empregando-se o Kit BioRad Protein Assay (BIO-RAD, Hercules, CA EUA). A mistura da reação continha $20 \mu \mathrm{L}$ do extrato protéico e $200 \mu \mathrm{L}$ do reagente e a determinação da absorbância foi realizada em $595 \mathrm{~nm}$ A curva padrão foi preparada utilizando-se albumina do soro bovino (BSA) (SIGMA, St. Louis, MO, EUA).

A análise de oxidação protéica foi realizada de acordo com o método de Levine (1990) e o conteúdo de carbonil foi calculado a partir da absorbância a $374 \mathrm{~nm}$, dividida pelo coeficiente de extinção para hidrazonas alifáticas (22 L nmo ${ }^{1} \mathrm{~cm}^{-1}$ ) e expresso em nmol de carbonil $\mathrm{mg}^{-1} \mathrm{de}$ proteína. As reações das proteínas oxidadas com 2,4 dinitrofenilhidrazina, segundo Levine (1990), são:

Proteína $-\mathrm{C}=\mathrm{O} \quad \mathrm{H}_{2} \mathrm{~N}-\mathrm{NH}-2,4 \mathrm{DNP}$ Proteína $=\mathrm{N}-\mathrm{NH}-2,4 \mathrm{DNP}+\mathrm{H}_{2} \mathrm{O}$

Proteína $-\mathrm{C}=\mathrm{N}-$ Proteína $\mathrm{H}_{2} \mathrm{~N}-\mathrm{NH}-2,4 \mathrm{DNP}$

Proteína $=\mathrm{N}-\mathrm{NH}-2,4 \mathrm{DNP}+\mathrm{H}_{2} \mathrm{O}$

Para análise de peroxidação lipídica radicular, foi utilizado o método de TBARS
(Thiobarbituric acid reative substances), proposto por Buege \& Aust (1978), com algumas modificações (Souza, 2003). O TBA forma complexos de cor avermelhada, com aldeídos de baixa massa molecular, como o malondialdeído (MDA), produto secundário do processo de peroxidação. A concentração do complexo MDATBA foi calculada pela seguinte equação: [MDA] $=\left(\mathrm{A}_{535}-\mathrm{A}_{600}\right) /(\xi . \mathrm{b})$, em que: $\xi$ (coeficiente de extinção $=1,56 \times 10^{-5} \mathrm{~cm}^{-1}$ ) e b: (comprimento ótico $=1)$. A peroxidação foi expressa em nmol (MDA) $\mathrm{g}^{-1}$ de matéria fresca.

O método utilizado para análise da peroxidação lipídica foliar foi o mesmo da análise radicular, proposto por Buege \& Aust (1978), com modificações de Viana (2002).

\section{Resultados e Discussão}

De maneira geral, os teores de proteínas totais nas raízes de plântulas das cultivares BR 107 e Saracura apresentaram o mesmo padrão de distribuição, em relação ao tempo de encharcamento, diminuindo até o período de 72 h, com exceção do ciclo 1, de até 96 h, e aumentando, logo em seguida, até as 144 h de estresse (Figuras 1 e 2).

Nas primeiras $72 \mathrm{~h}$ de encharcamento contínuo, as plântulas de todos os genótipos responderam ao estresse prolongado, ocorrendo degradação protéica. Após esse período, possivelmente houve uma recuperação parcial dessas plântulas, com síntese de novas proteínas.

No período não encharcado, os teores de proteínas nas raízes do Saracura foram $40 \%$ e $60 \%$ superiores àqueles encontrados no BR 107 , respectivamente, no $\mathrm{C} 1, \mathrm{C} 8$ e $\mathrm{C} 16$ e conseguiram manter teores mais elevados que a testemunha até o período de $48 \mathrm{~h}$. Esses resultados sugerem que, no milho Saracura, algum mecanismo seja acionado, favorecendo a síntese ou protegen- 
do as proteínas da degradação, quando exposto a ambientes com baixos níveis de oxigênio.

$\mathrm{Na}$ literatura, tem sido mostrado que, sob condições de anoxia ou hipoxia, a síntese protéica é limitada, ocorrendo variações consideráveis na qualidade das proteínas que estão sendo sintetizadas (Sacks et al., 1980). Nesse contexto, a síntese de algumas delas é aumentada e a de outras é diminuída e até mesmo inibida. De maneira geral, aquelas proteínas que têm sua síntese aumentada ou diminuída/inibida, naquelas condições, estão relacionadas aos metabolismos anaeróbico e aeróbico, respectivamente. Os dados obtidos neste experimento estão em concordância com Sacks et al. (1996), que relataram que, durante a anaerobiose em milho, há uma imediata repressão na síntese de proteínas preexistentes e, posteriormente, há síntese seletiva de aproximadamente 20 polipeptídios. Muitos desses são proteínas anaeróbicas (ANP's), envolvidas com a glicólise.

Dentre as ANP's estão álcool desidrogenase (ADH) (Sacks et al., 1980; Sacks et al., 1996), aldolase (Kelley \& Tolan, 1999), gliceraldeído-3-fosfato desidrogenase (Pinto, 2004; Russel \& Sachs, 1991), sacarose sintase (Springer et al., 1986), enolase e glicose-6-fosfato isomerase (Kelley \& Freeling, 1984).

Quanto à oxidação das proteínas das raízes, observou-se que houve um aumento generalizado para o genótipo BR 107 e ciclos 8 (C8) e 16 (C16) do Saracura, até as $72 \mathrm{~h}$ de encharcamento. No ciclo 1 (C1), esse aumento ocorreu até 96 h (Figuras 3 e 4). A cultivar BR 107 apresentou valores mais elevados para essa característica e os resultados mostram uma relação inversa entre concentração e oxidação de proteínas, confirmando, com isso, a influência do estresse de oxigênio nessas duas características.
Segundo Palma et al. (2002), níveis basais de grupos carbonil detectados em plantas são gerados em processos fisiológicos normais, justificando os níveis encontrados nas plantas controle. A diminuição da proteína oxidada, após $72 \mathrm{~h}$ de encharcamento, possivelmente está ligada ao aumento de substâncias antioxidantes e à diminuição de espécies reativas de oxigênio (EROS). Segundo Henriques et al. (2001), as proteções celulares contra os efeitos das EROS são o aumento da atividade de enzimas antioxidantes
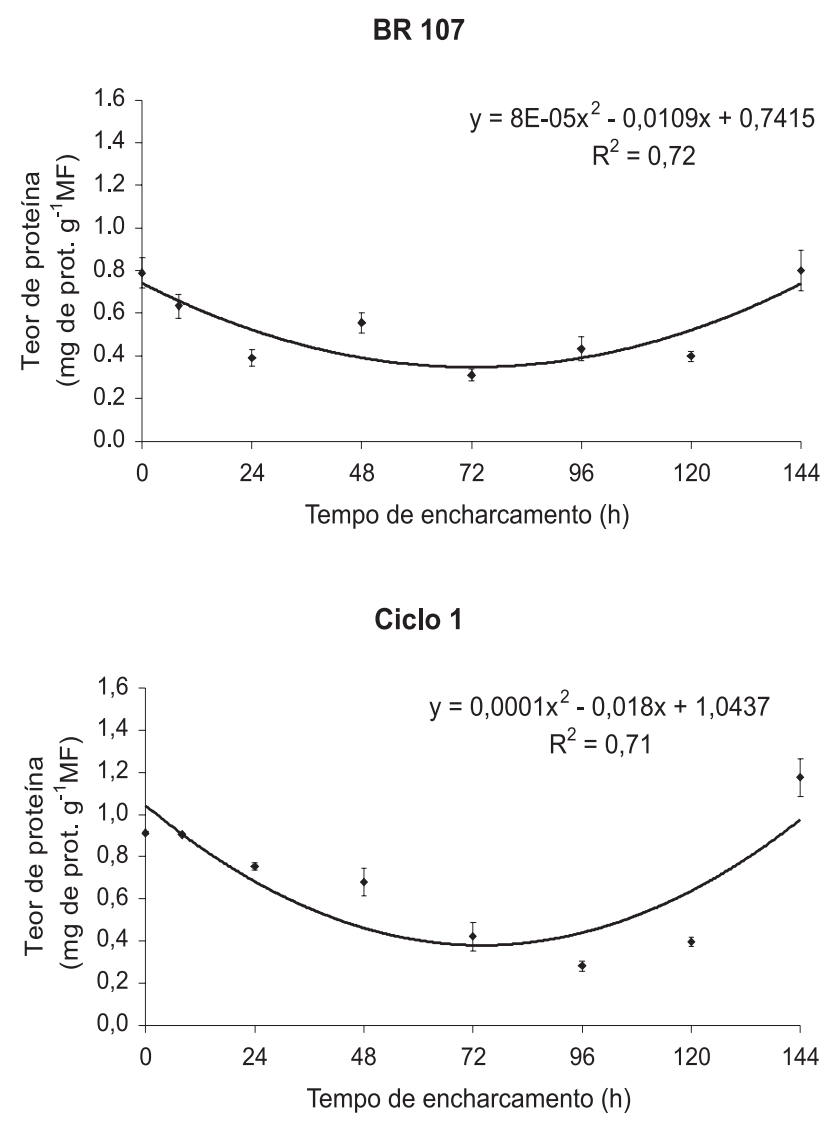

FIGURA 1. Teor de proteína total em raízes de plântulas da cultivar BR 107 e do ciclo 1 de seleção do Saracura, nos períodos de $0,8,24,4872,96,120$ e $144 \mathrm{~h}$, sob encharcamento contínuo. Os valores de cada cultivar representam a média de três repetições \pm erro padrão da análise de variância, $p<0,01$. Sete Lagoas, MG, 2005.

Revista Brasileira de Milho e Sorgo, v.4, n.3, p.362-373, 2005 
e a produção de antioxidantes como a glutationa e o ácido ascórbico.

Estresses abióticos, como toxidez de alumínio em milho sensível (Boscolo et al., 2003) e exposição a ozônio em feijão (Phaseolus vulgaris L.) (Junqua et al., 2000; Leitão et al., 2003), têm causado aumento na oxidação de proteínas, sendo diretamente proporcional ao tempo de exposição ao alumínio e ao ozônio, respectivamente. Ainda segundo Leitão et al. (2003), o ozônio induz à formação de derivados do carbonil, com visível dano foliar.
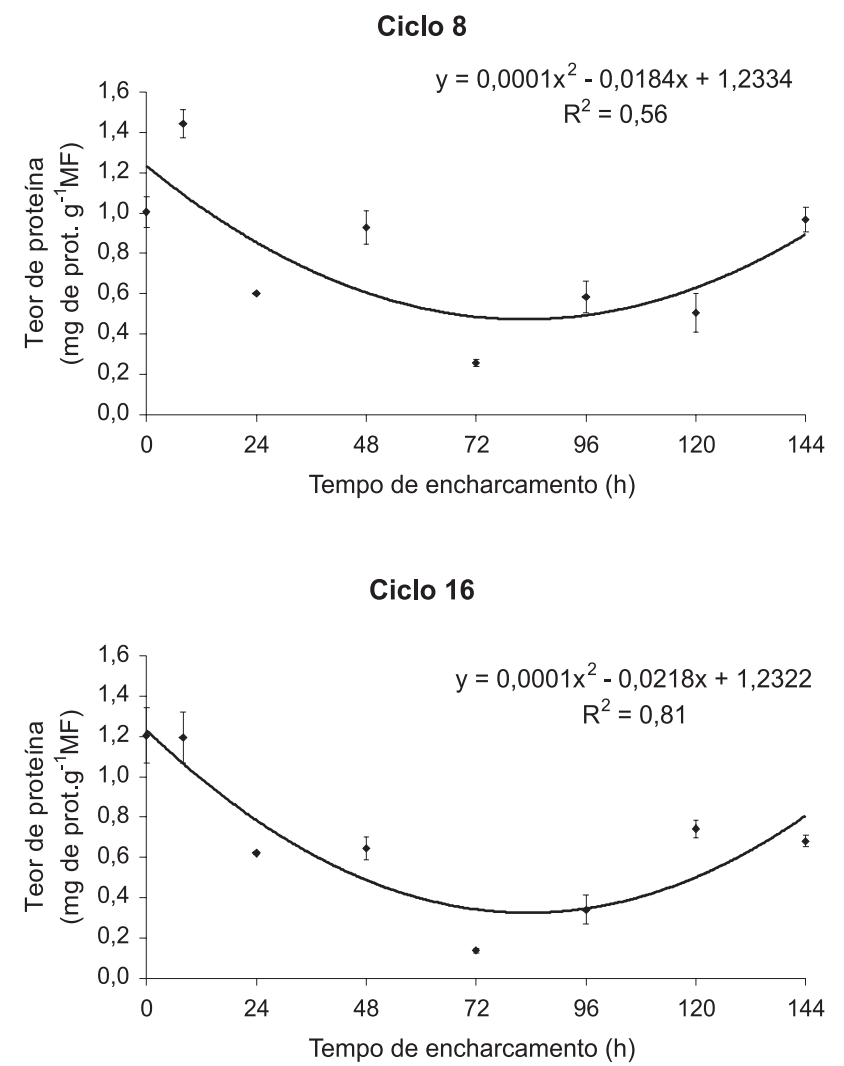

FIGURA 2. Teor de proteína total em raízes de plântulas dos ciclos 8 e 16 de seleção do Saracura, nos períodos de $0,8,24,72,96,120$ e 144 h, sob encharcamento contínuo. Os valores de cada cultiva representam a média de três repetições \pm erro padrão da análise de variância, $\mathrm{p}<0,01$. Sete Lagoas, $\mathrm{MG}$, 2005.
Tanto as plântulas da cultivar BR 107 quanto as dos ciclos de seleção do Saracura apresentaram a mesma tendência de concentração e oxidação de proteínas, sob encharcamento. Entretanto, para a maioria dos tempos de encharcamento, os ciclos de seleção apresentaram valores maiores e menores, respectivamente, para concentração e oxidação protéica. Esses resultados sugerem que a seleção para o encharcamento contribuiu para uma melhora no mecanismo de proteção, em relação a essas características nos estádios de plântulas V3-V5.
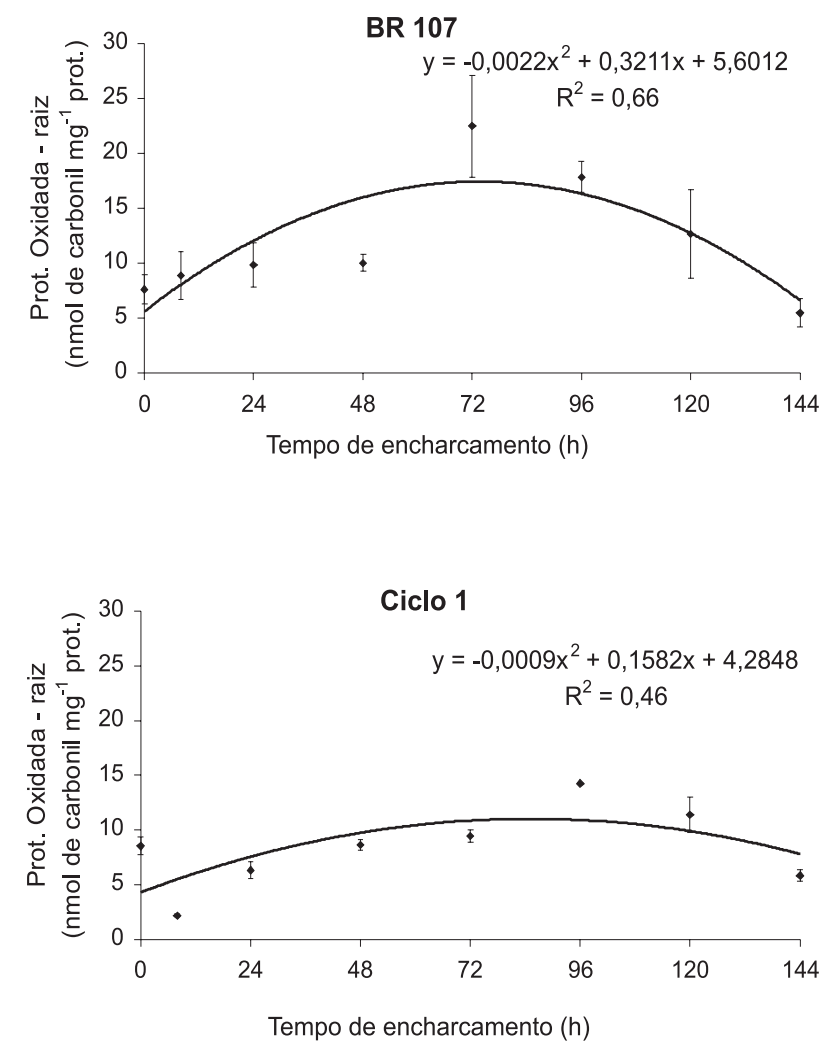

FIGURA 3. Oxidação protéica em raízes de plântulas da cv. BR 107 e ciclo 1 de seleção do Saracura, nos períodos de $0,8,24,48,72,96,120$ e $144 \mathrm{~h}$, sob encharcamento contínuo. Os valores de cada cultivar representam a média de três repetições \pm erro padrão da análise de variância, $\mathrm{p}<0,01$. Sete Lagoas, $\mathrm{MG}$, 2005.

Revista Brasileira de Milho e Sorgo, v.4, n.3, p.362-373, 2005 
É importante destacar que o Saracura foi desenvolvido para tolerar encharcamento intermitente e não contínuo, a partir do estádio V6. Portanto, estão em andamento pesquisas que levam em consideração os aspectos qualitativos das proteínas do milho Saracura paralelamente ao conjunto desses componentes obtidos na variedade sensível BR 107.

Na peroxidação lipídica radicular, de maneira geral, ocorreu um decréscimo até $24 \mathrm{~h}$ de encharcamento contínuo e sucessivo aumento da peroxidação em $48 \mathrm{~h}$, com posterior decréscimo
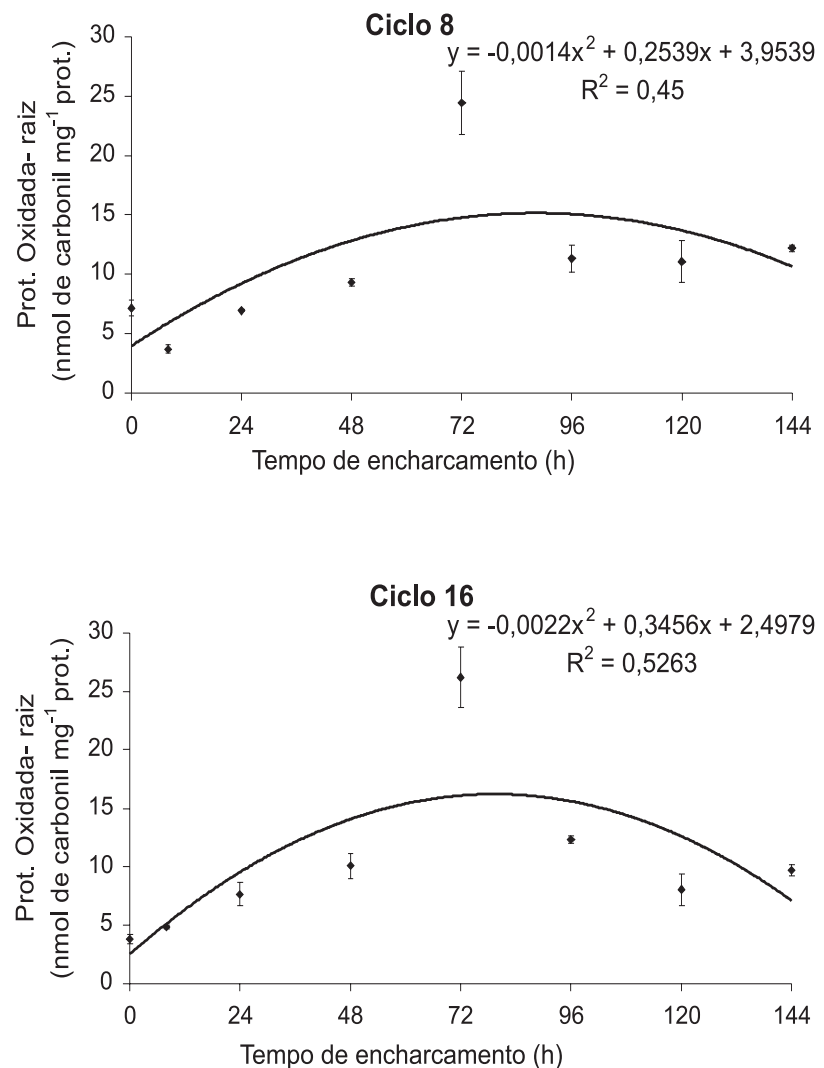

FIGURA 4. Oxidação protéica em raízes de plântulas dos ciclos 8 e 16 de selecãa do Saracura, nos períodos de $0,8,24,48,72,96,120$ e $144 \mathrm{~h}$, sob encharcamento contínuo. Os valores de cada cultivar representam a média de três repetições \pm erro padrão da análise de variância, $\mathrm{p}<0,01$. Sete Lagoas, $\mathrm{MG}$, 2005. até $72 \mathrm{~h}$ (Figuras 5 e 6). Por outro lado, nas folhas, houve um aumento da peroxidação em $24 \mathrm{~h}$ e posterior decréscimo em $48 \mathrm{~h}$ (Figuras 7 e 8).

Analisando-se os gráficos de peroxidação radicular e foliar, nota-se que, quando existe uma maior peroxidação na parte área, existe uma menor no sistema radicular e vice-versa. Esse parece ser um mecanismo utilizado pelas plântulas, nos genótipos observados, em resposta ao estresse prolongado.

Segundo Blokhina et al. (2002), a peroxidação lipídica (PL) é o processo metabólico
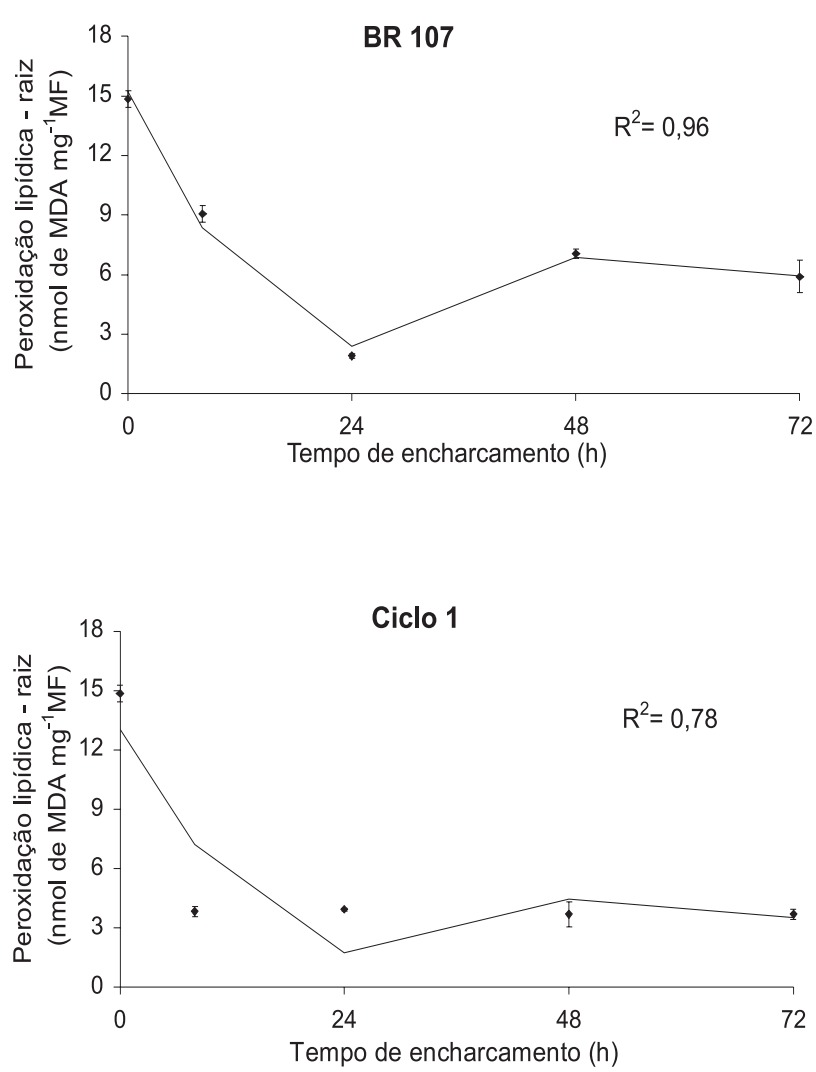

FIGURA 5. Peroxidação lipídica em raízes de plântulas da cv. BR 107 e do ciclo 1 de seleção do Saracura, nos períodos de $0,8,24,48$ e $72 \mathrm{~h}$, sob encharcamento contínuo. As curvas foram ajustadas pela da equação: $\mathrm{y}=\mathrm{a}+\mathrm{bx}+\mathrm{cx}^{2.5}+\mathrm{dx}^{3}$. MDA - malondialdeído. Os valores de cada cultivar representam a média de três repetições \pm erro padrão da análise de variância, $\mathrm{p}<0,01$. Sete Lagoas, MG, 2005.

Revista Brasileira de Milho e Sorgo, v.4, n.3, p.362-373, 2005 
que ocorre em condições naturais, o que explica os altos valores de peroxidação encontrados nas raízes e folhas, nas plantas-controle. É importante destacar que, nas plântulas da cultivar BR 107, os níveis de peroxidação tanto radicular quanto foliar, foram maiores que os encontrados nos ciclos do Saracura, no período não encharcado.

Os ácidos graxos insaturados, principais componentes das membranas, são susceptíveis à peroxidação. A fase inicial da PL inclui redução do $\mathrm{O}_{2}$, formando as espécies reativas de oxigênio (EROS). O radical hidroxila e o oxigênio
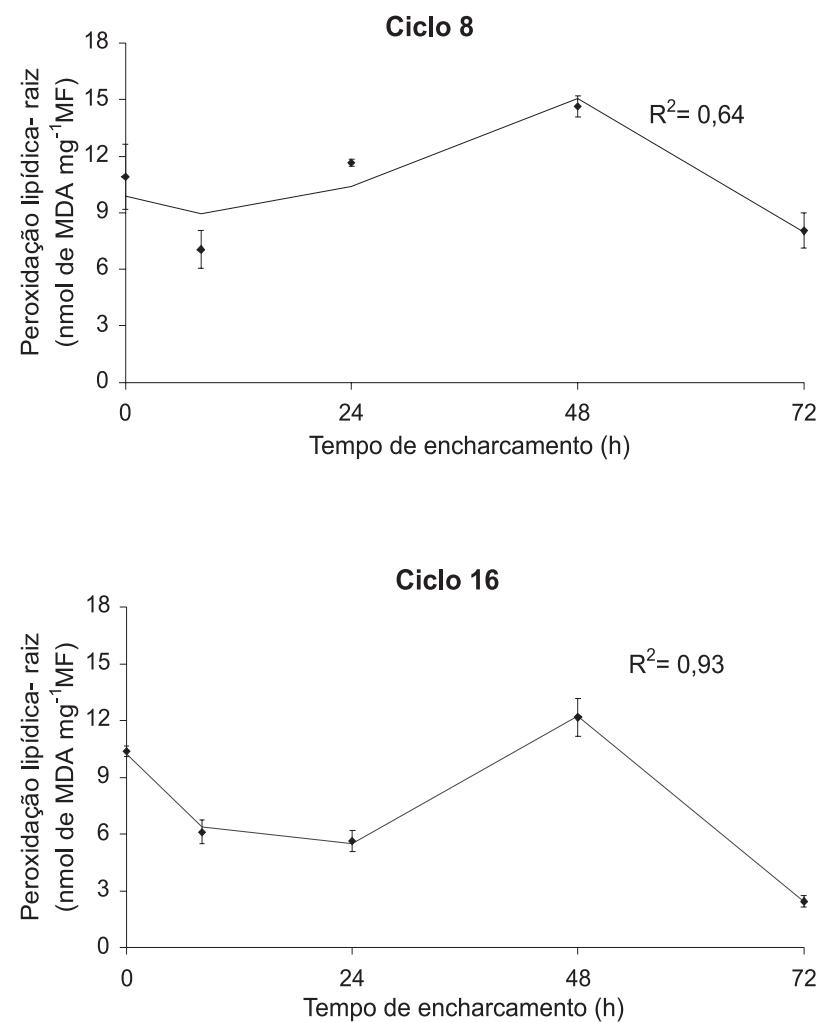

FIGURA 6. Peroxidação lipídica em raízes de plântulas dos ciclos 8 e 16 de seleção do Saracura nos períodos de $0,8,24,48$ e $72 \mathrm{~h}$, sob encharcamento contínuo. As curvas foram ajustadas através da equação: $y=a+b x+c x^{2.5}+d x^{3}$. MDA - malondialdeído. Os valores de cada cultivar representam a média de três repetições \pm erro padrão da análise de variância, $\mathrm{p}<$ 0,01. Sete Lagoas, MG, 2005. singleto reagem com os ácidos graxos das membranas, formando dienos conjugados, radicais lipoperóxidos e hidroperóxidos (Smirnoff, 1995).

Vários trabalhos ilustram o aumento da peroxidação lipídica, sob diversos tipos de estresse: seca, em aroeira do sertão (Myracrodruon urundeuva) (Queiroz et al., 2002) e milho (Viana, 2002), altas doses de chumbo, em arroz (Verma \& Dubey, 2003), estresse por alumínio, em soja (Cakmak \& Horst, 1991), ervilha (Yamamoto et al., 2001) e
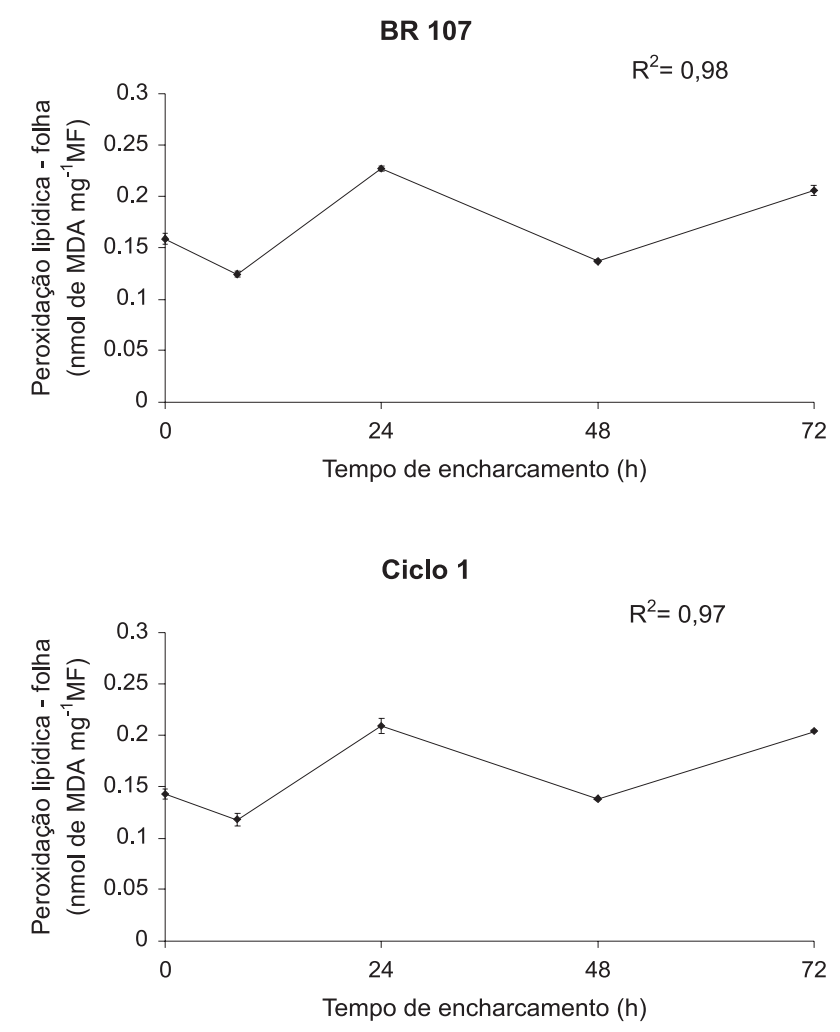

FIGURA 7. Peroxidação lipídica em folhas de plântulas da cultivar BR 107 e do ciclo 1 de seleção do Saracura, nos períodos de 0, 8, 24, 48 e 72 h, sob encharcamento contínuo. As curvas foram ajustadas através da equação: $y=a+b x+c x^{1.5}+d^{2}+e^{3}$. MDAmalondialdeído. Os valores de cada cultivar representam a média de três repetições \pm erro padrão da análise de variância, p <0,01. Sete Lagoas, MG, 2005.

Revista Brasileira de Milho e Sorgo, v.4, n.3, p.362-373, 2005 
sorgo (Sorghum bicolor) (Peixoto et al., 1999), estresse por frio, em café (Queiroz et al., 1998) e outros.

Em folhas de feijão submetidas a altas doses de herbicida, ocorreu um aumento da PL, acompanhado de um aumento na atividade da enzima redutase da glutationa (GR), que induziu a queda da PL. O aumento da produção de antioxidantes, combinado com a atividade de enzimas antioxidantes, parece ser a principal estratégia para limitar a peroxidação lipídica em plantas (Schmith \& Kunert, 1986).
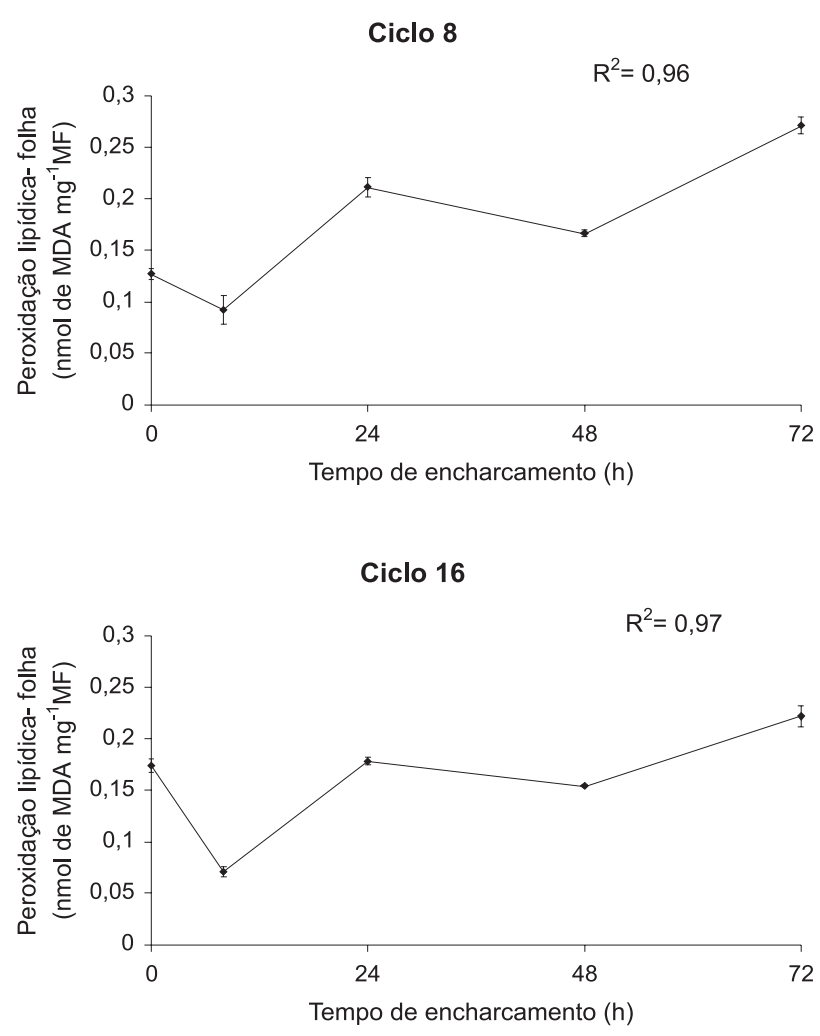

FIGURA 8. Peroxidação lipídica em folhas de plântulas dos ciclos 8 e 16 de seleção do Saracura, nos períodos de $0,8,24,48$ e $72 \mathrm{~h}$, sob encharcamento contínuo. As curvas foram ajustadas pela equacão: y $=\mathrm{a}+\mathrm{bx}+\mathrm{cx}^{1.5}+\mathrm{dx}^{2}+\mathrm{ex}^{3}$. MDA - malondialdeído. Os valores de cada cultivar representam a média de três repeticões \pm erro padrão da análise de variância, $\mathrm{p}<$ 0,01. Sete Lagoas, MG, 2005.
Em estresse por alumínio, em milho, nas linhagens tolerante e tolerante intermediária, as taxas de peroxidação ficaram próximas às do controle. Nesse caso, níveis baixos de eventos oxidativos de PL sugerem que, possivelmente, está havendo atuação de mecanismos de detoxificação dos radicais livres, contribuindo para o aumento da tolerância ao alumínio (Souza, 2003). Além disso, as plantas podem minimizar os danos causados pelo estresse oxidativo, reduzindo as espécies reativas de oxigênio e ou removendo-as, por meio da atuação de enzimas antioxidantes, como a redutase da glutationa (GR), peroxidase do ascorbato (APx), catalase (CAT) e superóxido dismutase (SOD) (Price \& Hendry, 1991).

Outros trabalhos relacionam o aumento da atividade de enzimas antioxidantes como mecanismo de defesa, degradando espécies reativas de oxigênio e favorecendo a diminuição da peroxidação lipídica (Aziz \& Larher, 1998; Peixoto et al., 1999; Verma \& Dubey, 2003). Yan et al. (1996), trabalhando com uma cultivar de milho sensível ao encharcamento, encontraram um aumento progressivo na PL até sete dias, com decréscimo da atividade de enzimas antioxidantes.

Os resultados encontrados neste trabalho, mesmo não apresentando diminuição progressiva e linear da PL, mostram uma adaptação ao encharcamento intermitente das plântulas de milho de todos os genótipos, para o evento da PL, no estádio anterior ao V6, uma vez que tiveram a mesma tendência, tanto para a peroxidação radicular quanto foliar, e essa tendência parece correlacionar parte aérea e radicular, como descrito.

\section{Conclusões}

Os resultados do teor e oxidação protéicos, peroxidação lipídica radicular e foliar foram responsivos ao encharcamento e mostraram

Revista Brasileira de Milho e Sorgo, v.4, n.3, p.362-373, 2005 
adaptações das plântulas de milho ao estresse prolongado, obtendo, basicamente, a mesma tendência nos genótipos analisados.

\section{Literatura Citada}

AMICI, A.; LEVINE, R. L.; TSAI, L.; STADMAN, E. R. Convertion of amino acid homopolymers to carbonyls derivates by metalcatalysed oxidations reactions. Journal of Biological Chemistry, Baltimore, v. 264, n. 6, p. 3341-3346, Feb. 1989.

AZIZ, A.; LARHER, F.; Osmotic stress induced changes in lipid composition and peroxidation in leaf discs of Brassic nappus L. Journal of Plant Physiology, Jena, v. 153, n. 5/6, p. 754 762, Nov. 1998.

BLOKHINA, O.; VIROLAINEM, E.; FAGERSTEDT, K. V. Antioxidants, oxidative damage and oxygen deprivation stress: a review. Annals of Botany, Oxford, v. 91, p. 179-194, Jan. 2002.

BOR, M.; ÖZDEMIR, F.; TÜRKAN, I. The effect of salt stress on lipid peroxidation and antioxidants in leaves of sugar beet Beta vulgaris L. and wild beet Beta maritime L. Plant Science, Clare, v. 164, n. 1, p. 77-84, Jan. 2003.

BOSCOLO, P. R. S.; MENOSSI, M.; JORGE, R. A. Aluminum-induced stress oxidative in maize. Phytochemistry, Oxford, v. 62, n. 2, p 181-189, Jan. 2003.

BRADFORD, J. M. A rapid and sensitive method for quantification of microgram quantities of protein utilizing the principle of protein-dye binding. Analytical Biochemistry, New York, v. 72, p. 248, 1976

BUEGE, J. A.; AUST, S. D. Microsomal lipid peroxidation. Methods in Enzymology, Oxford, v. 52, p. 302-310, 1978.
CAKMAK, I.; HORST, W. J. Effect of aluminium on lipid peroxidation, superoxide dismutase, catalase and peroxidase activities in root tips of soybean (Glycine max). Physiologia Plantarum, Copenhagen, v. 83, n. 4, p. 463-468, Aug. 1991.

DAVIES, K. J. Protein damage and degradation by oxygen radicals. I. general aspects. The Journal of Biology Chemistry, Baltimore, v. 262, n. 20, p. 9895-9901, July 1987.

ELSTNER, E. F.; OSSWALD, W. Mechanisms of oxygen activation during plant stress. Proccedings of the Royal Society of Edinburgh, Edington, v. 102B, p. 131-154, 1994.

HENRIQUES, A. P.; DAFRÉ, A. L.; PICADA, J. N.; MARIS, A. F.; SALVADOR, M. Espécies reativas de oxigênio e avaliação de antioxidantes em sistemas biológicos. In: SERAFINI, L. A.; BARROS, N. M.; AZEVEDO, J. L. Biotecnologia na agricultura e na agroindústria. Guaíba: Agropecuária, 2001. p. 227-252.

HURNG, W. P.; KAO, C. H. Lipid peroxidation enzymes in senescing tobacco leaves during postflooding. Plant Science, Clare, v. 96, n. 1/2, p. 41-44, 1994

JUNQUA, M.; BIOLLEY, J-P.; PIE, S.; KANOUN, M.; DURAN, R.; GOULAS, P. In vivo occurrence of carbonyl in Phaseolus vulgaris proteins as a direct consequence of a chronic ozone stress. Plant Physiology Biochemistry, Paris, v. 38, n. 11, p. 853-861, Nov. 2000.

KELLEY, P. M.; FREELING, M. Anaerobic expression of maize fructose-1-6 diphosfate aldolase. Journal of Biological Chemistry, Baltimore, v. 259, n. 22, p. 14180-14183, 1984.

KELLEY, M. P.; TOLAN, D. R. The complete amino acid sequence for the anaerobically 
induced aldolase from maize derived from cDNA clones. Plant Physiology, Rockville, v. 82, n. 1, p. 199-203, Jan. 1999.

LEITAO, L.; GOULAS, P.; BIOLLEY, J-P. Timecourse of Rubisco oxidation in beans (Phaseolus vulgaris $\mathrm{L}$.) subjected to a long-term ozone stress. Plant Science, Clare, v. 165, n. 3, p. 613-620, Sept. 2003.

LEVINE, R. L.; GALARD, D.; OLIVIER, C. N.; AMICI, A.; CLIMENTE, I.; LENZ, A. G.; AHN, B. W.; SHALTIEL, S.; STADTMAN, E. R. Determination of carbonyl content in oxiedatively modified proteins. Methods Enzymology, Oxford, v. 186, p. 464-478, 1990.

PALMA, J. M.; SANDALIO, L. M.;CORPAS, F J.; ROMERO-PUERTAS, M. C.; McCARTHY, I.; DEL-RIO, L. A. Plant proteases, protein degradation, and oxidative stress: role of peroximes. Plant Physiology and Biochemistry, Paris, v. 40, n. 6/8, p. 521-530, June/Aug. 2002

PARENTONI, N. P.; GAMA, E. E. G.; MAGNAVACA,R.; MAGALHÃES, P. C. Seleção para tolerância ao encharcamento em milho (Zea mays L.). In: SIMPOSIO INTERNACIONAL SOBRE ESTRESSE AMBIENTAL, 1., 1992, Belo Horizonte. O milho em perspectiva: anais. Sete Lagoas: EMBRAPACNPMSCIMMYT/UNDP, 1995. p.433-439 .

PEIXOTO, P. H. P.; CAMBRAIA, J.; SANT'ANNA， R.; MOSQUIM， P. R.; MOREIRA. M. A. Aluminum effects on lipid peroxidation and activies of enzymes of oxidative metabolism in sorghum. Revista Brasileira de Fisiologia Vegetal, Brasília, DF, v. 11, n. 3, p. 137-143, set./dez. 1999.

PINTO, A. C. Genes induzidos por tratamento com cálcio em raízes do milho (Zea mays
L.) - BRS 4154 em condições de hipoxia. 2004. 55 p. Dissertação (Mestrado em Fisiologia Vegetal) - Universidade Federal de Lavras, Lavras.

PORTO, M. P. Método de seleção de plantas de milho para tolerância ao encharcamento do solo. Pesquisa Agropecuária Gaúcha, Porto Alegre, v. 3, n. 2, p. 187-190, 1997.

PRICE, A. H.; HENDRY, A. Iron- catalysed oxygen radical formation and its possible contribution to drought damage in nine native grasses and three cereals. Plant Cell Environment, Oxford, v. 14, n. 5, p. 477-484, June 1991.

QUEIROZ, C. G. S.; ALONSO, A.; MARESGUIA, M.; MAGALHÃES, A. C. Chillinginduced changes in membrane fluidity and antioxidant enzyme activities in Coffea arabica L. roots. Biology Plantarum, Prague, v. 41, n. 3 , p. 403-413, 1998.

QUEIROZ, C. G. S.; GARCIA, Q. S.; FILHO, J. P. L. Atividade fotossintética de lipídios de membrana em plantas de aroeira-do-sertão sob estresse hídrico e após reidratação. Braziliam Journal of Plant Physiology, Londrina, v. 14, n. 1, p. 5963, Jan./Apr. 2002.

RUSSELL, D. A.; SACHS, M. M. The maize glyceraldeyde-3-phosphate dehydrogenase gene family: organ-specific expression and genetic analysis. Molecular and General Genetics, New York, v. 229, n. 2, p. 219-228, Oct. 1991.

SACKS, M. M.; FREELING, M.; OKIMOTO, R. The anaerobic protein of maize. Cell, Cambridge, v. 20, n. 3, p. 761-767, 1980.

SACKS, M. M.; SUBBAIAH, C.; SAAB, I. Anaerobic gene expression and flooding tolerance in maize. Journal of Experimental Botany, Oxford, v. 47, n. 294, p. 1-15, Jan. 1996. 
SHACTER, E.; WILLIAMS, J. A.; LIM, M.; LEVINE, R. L. Differential susceptibility of plasma proteins to oxidative modification: examination by western blot immunoassay. Free Radical Biology and Medicine, Oxford, v. 17, n. 5, p. 429-437, Nov. 1994.

SCHMIDT, A.; KUNERT, K. J. Lipid peroxidation in higher plants. The role of glutathione reductase. Plant Physiology, Rockville, v. 82, n. 3, p. 700-702, Nov. 1986.

SILVA, A. R. Tolerância ao encharcamento. In SIMPÓSIO SOBRE ALTERNATIVAS AO SISTEMA TRADICIONAL DAS VÁRZEAS DO ESTADO DO RIO GRANDE DO SUL, 1984, Porto Alegre. Trabalhos apresentados.. Brasília, DF: PROVARZEAS / PROFIR, 1986. p. 1-19.

SMIRNOFF, N. The role of active oxygen in the response of plants to water deficit and desiccation. New Phytologist, Oxford, v. 125, n. 1, p. 27-58, Sept. 1993

SMIRNOFF, N. Antioxidant systems and response to the environment. In: SMIRNOFF, N. Environment and plant metabolism: flexibility and acclimation. Oxford: BIOS Scientific Publishers, 1995. p. 217-243.

SOUZA, J. B. Caracterização Fisiológica e Bioquímica de Linhagens de milho visando tolerância ao alumínio. 2003. 70 f. Dissertação (Mestrado em Biologia Vegetal) - Universidade Federal de Minas Gerais, Belo Horizonte.

SPRINGER, B.; WERR, W.; STALINGER, P.; BENNET, D. C.; ZOKOLICA, M.; FREELING, M. The shunken gene on chromosome 9 of Zea mays $\mathrm{L}$. is expressed in various plant tissue and encodes an anaerobic protein. Molecular and General Genetics, New York, v. 205, n. 3, p. 461$468,1986$.

STADTMAN, E. R. Protein oxidation and aging. Science, Washington, v. 257, n. 5074, p. $1220-$ 1224, 1992.

VERMA, S.; DUBEY, R. S. Lead toxicity induces lipid peroxidation and alters the activies of antioxidant enzymes in growing rice plants. Plant Science, Clare, v. 164, n. 4, p. 645-655, Apr. 2003.

VIANA, M. C. M. Déficit hídrico em genótipos de milho com tolerância diferencial à seca. 2002. 75 f. Dissertação (Mestrado em Biologia Vegetal) - Universidade Federal de Minas Gerais, Belo Horizonte.

SILVA, A. R. Tolerância ao encharcamento. In: SIMPÓSIO SOBRE ALTERNATIVAS AO SIS TEMA TRADICIONAL DAS VÁRZEAS DO ESTADO DO RIO GRANDE DO SUL, 1984, Porto Alegre. Trabalhos apresentados.. Brasília, DF: PROVARZEAS / PROFIR, 1986. p. 1-19.

YAMAMOTO, Y.; KOBAYASHI, Y.; MATSUMOTO, H. Lipid peroxidation is an early symptom triggered by aluminum, but not primary cause of enlogation inhibition in pea roots. Plant Physiology, Rockville, v. 125, n. 1, p. 199-208, Jan. 2001.

YAN, B.; DAI, Q.; LIU, X.; HUANG, S.; WANG, Z. Flooding-induced membrane damage, lipid oxidation and activated oxygen generation in corn leaves. Plant and Soil, Dordrecht, v. 179, n. 2, p. 261-268, Feb. 1996. 